\title{
Effect of partial drying and desiccation on somatic seedling quality in Norway and Serbian spruce
}

\author{
Teresa Hazubska-Przybył • Mikołaj Wawrzyniak • \\ Agata Obarska $\cdot$ Krystyna Bojarczuk
}

Received: 1 August 2014/Revised: 21 November 2014/ Accepted: 24 November 2014/Published online: 4 December 2014

(C) The Author(s) 2014. This article is published with open access at Springerlink.com

\begin{abstract}
Somatic embryo quality is still a problem for many researchers. To improve the efficiency of germination, special procedures are used, such as partial drying of somatic embryos at high relative humidity or desiccation in the presence of supersaturated solutions of salt. In this work, cotyledonary somatic embryos of Norway spruce (Picea abies) and Serbian spruce (P. omorika) were placed on culture media (ME or BM-5) to germinate. We found that after 4 weeks of incubation on these media, hypocotyl and radicle growth of control (non-dried) somatic embryos of both species was not adequate to yield seedlings able to acclimatize to greenhouse conditions. Therefore, somatic embryos were partly dried at relative humidity of $97 \%$ or desiccated at relative humidity of $79 \%$, for 2 or 3 weeks, and then placed on the Margara (ME) medium. Partial drying of somatic embryos at the higher relative humidity (97\%) enabled an improvement of radicle growth of germinating somatic embryos in both species. The highest conversion rate (45\%) was obtained for embryos of Norway spruce maintained for 2 weeks at relative humidity of $97 \%$. This treatment contributed to the improvement of germination and conversion efficiency of somatic embryos of Norway spruce, regardless of the drying period. Improved radicle growth facilitated development of better quality seedlings of this spruce species. In Serbian spruce,
\end{abstract}

Communicated by J. van Staden.

T. Hazubska-Przybył $(\bowtie) \cdot$ A. Obarska $\cdot$ K. Bojarczuk Institute of Dendrology, Polish Academy of Sciences, Parkowa 5, 62-035 Kórnik, Poland

e-mail: hazubska@o2.pl

M. Wawrzyniak

University of Life Sciences, Wojska Polskiego 28,

60-637 Poznań, Poland we did not obtain seedlings of sufficient quality, due to poor hypocotyl growth. Desiccation at humidity of $79 \%$ for 3 weeks proved to be lethal to somatic embryos of both species.

Keywords Picea - Relative humidity - Germination · Conversion $\cdot$ Somatic embryos

$\begin{array}{ll}\text { Abbreviations } \\ \text { ABA } & \text { Abscisic acid } \\ \text { BA } & \text { 6-Benzyladenine } \\ \text { BM-5 } & \text { Gupta and Holmstrom medium } \\ \text { ME } & \text { Margara medium } \\ \text { PEG } & \text { Polyethylene glycol } \\ \text { Picloram } & \text { 4-Amino-3,5,6-trichloropicolinic acid }\end{array}$

\section{Introduction}

Somatic embryogenesis is an alternative to traditional methods of tree propagation (from seeds or vegetatively). It makes a lot of genetically valuable plant material available in a short time.

Proper germination of somatic embryos enables their conversion into seedlings. The conversion of embryos into somatic seedlings is indicated by development of both functional radicle and shoot system (Hay and Charest 1999). This is a key step to the transfer of plants from in vitro culture to natural conditions.

The quality of somatic seedlings is largely determined by nutritional, physical and chemical conditions applied during the successive stages of somatic embryogenesis (Lazzeri et al. 1987). To date, for some conifer species, the 
effect of various environmental factors on the germination of somatic embryos has been studied (Uddin et al. 1989; Webster et al. 1990; Hay and Charest 1999; Hogberg et al. 2001). Some of the first factors studied were: medium composition, light versus dark culture, and position of embryos on the media (Uddin et al. 1989). In later studies, more attention was paid to the effect of procedures applied during the development of somatic embryos of Norway spruce (Picea abies) from embryogenic tissue on their subsequent ability to germinate (Bozhkov and von Arnold 1998; Hogberg et al. 2001). Bozhkov and von Arnold (1998) demonstrated that polyethylene glycol (PEG) added to the medium at the stage of formation of embryos from embryogenic tissue of $P$. abies had an inhibitory effect on further development of somatic embryos. In turn, Hogberg with team (2001) showed a similar effect of abscisic acid (ABA) on the development of somatic embryos in seedlings of this spruce species. Park et al. (1998) and Park (2002) emphasized that germination capacity depends only marginally on genetic factors. Therefore, to improve the quality of somatic seedlings, particular attention should be paid to environmental conditions during the germination stage (Stasolla and Yeung 2003).

To avoid problems with germination of somatic embryos of conifers, some researchers subjected them to partial drying at high relative humidity (Roberts et al. 1990, 1991; Attree et al. 1995; Find 1997; Jones and van Staden 2001) or desiccation in the presence of supersaturated solutions of salt (Roberts et al. 1990; Lelu et al. 1995; Dronne et al. 1997). These treatments result in dehydration of the embryos to varying extents and, consequently, improved efficiency of their germination and conversion into seedlings.

The aim of our study was to determine the effect of the two selected culture media, partial drying at high relative humidity, and desiccation, on germination and conversion of somatic embryos of two spruce species into seedlings.

\section{Materials and methods}

\section{Plant material}

Somatic embryos were obtained from embryogenic tissues of Norway spruce (Picea abies) and Serbian spruce ( $P$. omorika). They were induced from mature zygotic embryos taken from seeds gathered in the experimental forest 'Zwierzyniec' near Kórnik (provenance experiment, trees developed from seeds originating from Kolonowskie) and in the Kórnik Arboretum, respectively. Explants (zygotic embryos) were placed on half-strength Litvay's medium ( $1 / 2$ LM, Litvay et al. 1985) supplemented with 4-amino-3,5,6-trichloropicolinic acid (Picloram $9 \mu \mathrm{M}$ ), 6-benzyladenine (BA $4.5 \mu \mathrm{M}$ ), and sucrose (10 g/l). The same medium was used for maintenance of the induced embryogenic tissues of both species. Cotyledonary somatic embryos for germination were collected from two embryogenic lines (one for each species of spruce) grown for 5 weeks on $1 / 2$ LM medium supplemented with ABA $(20 \mu \mathrm{M})$, sucrose $(34 \mathrm{~g} / \mathrm{l})$, and Phytagel (agar substitute gelling agent, Sigma-Aldrich $6 \mathrm{~g} / \mathrm{l})$.

The experiments on germination were carried out based on the most productive lines in terms of number of cotyledonary somatic embryos per $1 \mathrm{~g}$ of embryogenic tissue.

\section{Experiment I: effect of culture media}

Somatic embryos of Norway spruce and Serbian spruce at the cotyledonary stage (Fig. 1) were selected and placed on two germination media: Margara medium (ME, Margara 1977) or Douglas-fir basic culture medium (BM-5, Gupta and Holmstrom 2005), without growth regulators but with sucrose $(20 \mathrm{~g} / \mathrm{l})$. They were cultured for 2 weeks in the dark, at $22 \pm 1{ }^{\circ} \mathrm{C}$, and for the next 2 weeks in blue-red LED light (light intensity $35 \mu \mathrm{M} \mathrm{m}^{-2} \mathrm{~s}^{-1}$ ). Subsequently, embryos were cultured on the same media for another month. For each species, 20 embryos were placed in one Petri dish (diameter $90 \mathrm{~mm}$ ). The experiment was performed at least twice, depending on the number of embryos at the cotyledonary stage obtained after treatment of embryogenic tissue with ABA.

After 4 weeks, the germination capacity of somatic embryos was determined and their growth was assessed, based on hypocotyl and radicle measurements. Conversion

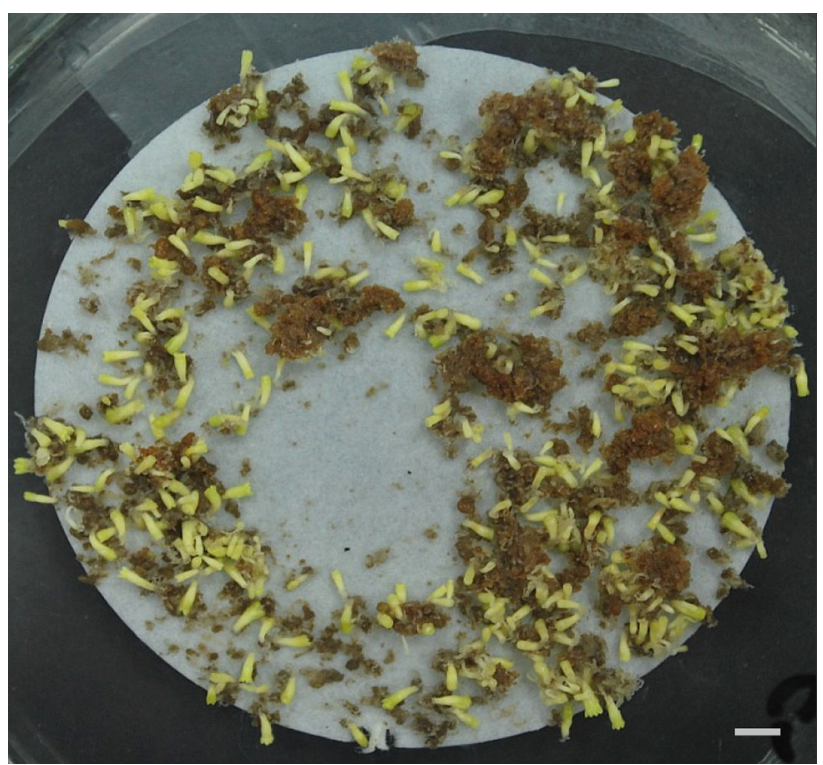

Fig. 1 Somatic embryos of Norway spruce (Picea abies) at the cotyledonary stage, taken for germination. Bar $5 \mathrm{~mm}$ 
rate was determined during the next month of incubation on the selected media. Somatic embryos were considered to be converted into seedlings if the hypocotyl was $\geq 10 \mathrm{~mm}$ and the radicle was $\geq 5 \mathrm{~mm}$ long, and if root hairs and primordia of apical buds appeared.

\section{Experiment II: effect of relative humidity}

The Petri dishes with about 20 cotyledonary somatic embryos per dish were placed in glass jars at relative humidity levels of 79 or $97 \%$, which were obtained by placing near the Petri dish a saturated saline solution $\left(\mathrm{NH}_{4}\right)_{2} \mathrm{SO}_{4}$ (Rockland 1960) or sterile-distilled water, respectively. Somatic embryos were subjected to both relative humidity levels for 2 and 3 weeks in the dark, at $22 \pm 1{ }^{\circ} \mathrm{C}$. In the control variant, embryos were not subjected to drying or desiccation. The experiment was performed three times.

To determine the water content of somatic embryos, they were weighed before and after exposure to the specific relative humidity levels. The water content of somatic embryos was determined on a fresh weight basis according to the standards set by the International Seed Testing Association (Roberts et al. 1990):

$\begin{aligned} \% \text { moisture content }= & \text { fresh } \mathrm{wt}-\text { dry wt } / \text { fresh } \mathrm{wt} \\ & \times 100\end{aligned}$

Somatic embryos after partial drying or desiccation were placed on the ME germination medium and incubated under the same conditions mentioned above. After 4 weeks of incubation, the germination capacity of somatic embryos was determined. As in the previous experiment, the ability of dried embryos to grow was evaluated based on measurements of hypocotyl and radicle length. Conversion rate was assessed as in Experiment I.

\section{Statistical analysis}

The Statistica ${ }^{\mathrm{TM}} 10$ (Statsoft Poland) package was used for data analysis. Data collected in Experiment I were analyzed using the Kruskal-Wallis test, while data from Experiment II were analyzed using the Tukey test (for uneven numbers of repetitions), at the significance level of $p>0.05$.

\section{Results}

Experiment I: effect of culture media

Somatic embryo germination capacity in both species of spruce was high and reached $\geq 90 \%$ regardless of the medium used (Table 1). Hypocotyl and radicle growth
Table 1 Germination capacity and conversion rate of non-dried somatic embryos of selected lines of Norway spruce (Picea abies) and Serbian spruce $(P$. omorika), depending on the applied medium (mean \pm standard error)

\begin{tabular}{cllll}
\hline Species & Medium & $\begin{array}{l}\text { No. of embryos } \\
\text { on medium }\end{array}$ & $\begin{array}{l}\text { Germination } \\
(\%)\end{array}$ & $\begin{array}{l}\text { Conversion } \\
(\%)\end{array}$ \\
\hline $\begin{array}{c}\text { Norway } \\
\text { spruce }\end{array}$ & ME & 258 & $99.31 \pm 0.70$ & $2.21 \pm 1.24$ \\
Serbian & ME & 102 & $98.41 \pm 1.59$ & $1.71 \pm 1.71$ \\
spruce & BM-5 & 277 & $92.55 \pm 2.07$ & $3.41 \pm 1.78$ \\
\hline
\end{tabular}

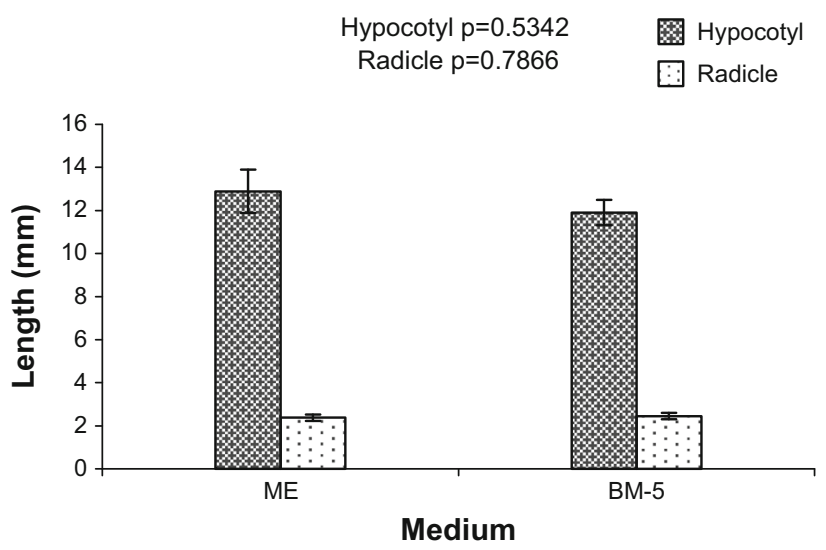

Fig. 2 Influence of incubation on the tested media on germination of somatic embryos of Norway spruce (Picea abies). Mean \pm standard error

began during the first 2 weeks of embryo incubation in the dark on both tested media. In the next weeks of incubation in the light, however, usually a marked growth of the hypocotyl was observed, while radicle growth was poor. Only a few embryos produced radicles $\geq 5 \mathrm{~mm}$ long, so conversion rate was very low: up to $2.2 \%$ for Norway spruce and up to $3.4 \%$ for Serbian spruce (Table 1).

In general, somatic embryos of Norway spruce were characterized by more intensive growth during incubation on both media, as compared to embryos of Serbian spruce (Figs. 2, 3). However, synchronization of hypocotyl and radicle growth for Norway spruce embryos were poorer. Hypocotyl length averaged about 13 and $12 \mathrm{~mm}$ for embryos incubated on the ME and BM-5 media, respectively (Fig. 2). Radicle length was about $2.2 \mathrm{~mm}$. In somatic embryos of Serbian spruce, better synchronization of hypocotyl and radicle growth was observed on the BM-5 medium (Fig. 3). Both hypocotyl and radicle lengths were about $3 \mathrm{~mm}$. However, some abnormalities in the structure of embryos of both species were observed (swollen hypocotyl, poorly developed cotyledons) on the BM-5 medium. On the ME medium, the hypocotyl of somatic embryos of Serbian spruce reached an average length of $5 \mathrm{~mm}$, and 


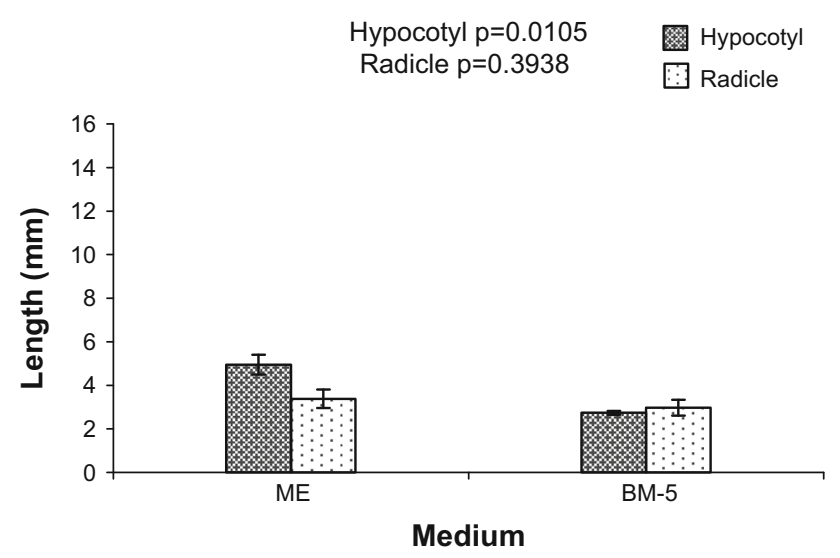

Fig. 3 Influence of incubation on the tested media on germination of somatic embryos of Serbian spruce (Picea omorika). Mean \pm standard error

radicle length of $3.7 \mathrm{~mm}$ (Fig. 3). There were no significant differences in the growth of both plant organs for embryos of Norway spruce between culture media (Fig. 2). Significant differences in hypocotyl growth were noted for embryos of Serbian spruce (Fig. 3) where embryos cultured on the ME medium produced hypocotyls which were almost twice as long as those incubated on BM-5.

\section{Experiment II: effect of relative humidity}

After partial drying of somatic embryos at high relative humidity of $97 \%$, water content of the embryos was reduced by about $23 \%$ in Norway spruce and $26 \%$ in Serbian spruce (Table 2). Desiccation of embryos at relative humidity of $79 \%$ caused the water content to decrease by about $61 \%$ on average. We observed that duration of drying/desiccation at the specified relative humidity levels and the origin of embryos had a small effect on the reduction of water content in somatic embryos (Table 2).

The germination capacity of somatic embryos of Norway spruce was $100 \%$ after partial drying at relative humidity of $97 \%$, regardless of duration of the treatment (Table 3). However, after desiccation at relative humidity of $79 \%$, only around $5 \%$ embryos were able to germinate after 2 weeks of desiccation. If somatic embryos were desiccated longer, they lost the capacity to germinate (Table 3).

Also, somatic embryos of Serbian spruce reached $100 \%$ germination level after partial drying at high relative humidity for 3 weeks (Table 3), whereas the embryos subjected to $97 \%$ humidity for 2 weeks were characterized by a slightly lower germination capacity (92.06\%), which was comparable with the control $(92.55 \%)$. After desiccation of somatic embryos at relative humidity of $79 \%$, only $9 \%$ of embryos treated for 2 weeks were capable of
Table 2 Water content decrease in somatic embryos of Norway spruce (Picea abies) and Serbian spruce (P. omorika) subjected to partial drying or desiccation at specified relative humidity levels

\begin{tabular}{cllll}
\hline Species & $\begin{array}{l}\text { Relative } \\
\text { humidity } \\
(\%)\end{array}$ & $\begin{array}{l}\text { Drying } \\
\text { period } \\
(\text { weeks })\end{array}$ & $\begin{array}{l}\text { Water content } \\
\text { decrease }(\%)\end{array}$ & $\begin{array}{l}\text { Average water } \\
\text { content } \\
\text { decrease }(\%)\end{array}$ \\
\hline $\begin{array}{c}\text { Norway } \\
\text { spruce }\end{array}$ & 97 & 2 & $21.84 \pm 3.58$ & $23.22 \pm 6.99$ \\
& 79 & 3 & $24.59 \pm 10.39$ & \\
& & 2 & $60.97 \pm 3.20$ & $61.55 \pm 1.73$ \\
Serbian & 97 & 2 & $62.13 \pm 0.26$ & \\
spruce & & 3 & $24.64 \pm 8.74$ & $26.03 \pm 5.49$ \\
& 79 & 2 & $27.41 \pm 2.24$ & \\
& & 3 & $63.19 \pm 2.59$ & 62.87 \\
\hline
\end{tabular}

Mean \pm standard error

germination (Table 3). A longer desiccation period resulted in a lack of somatic embryo germination, as in Norway spruce.

Partial drying (at $97 \%$ relative humidity) of somatic embryos of Norway spruce contributed to the improved rate of their conversion into seedlings, from $2 \%$ in the control to 45 and $42 \%$ for 2 and 3 weeks of treatment, respectively (Table 3 ). In contrast, somatic embryos desiccated at $79 \%$ relative humidity were not capable of conversion into seedlings.

For Serbian spruce, the rate of conversion of somatic embryos into seedlings was only slightly higher after incubation at relative humidity of $97 \%$ for 2 weeks than in the control (Table 3). Somatic embryos incubated at relative humidity of $79 \%$ were not capable of conversion into seedlings, as in the case of Norway spruce embryos.

Partial drying had a positive influence on the quality of somatic embryos of Norway spruce and Serbian spruce. After treatment of somatic embryos at high relative humidity (97\%), radicle growth in embryos of both species was improved, compared with the control (Figs. 4, 5). The desiccation of somatic embryos at relative humidity of $79 \%$ contributed to a significant lowering of the viability and growth of embryos, which prevented their further development into seedlings (Figs. 4, 5; Table 3).

After partial drying, the pattern of development of somatic embryos of Norway spruce seedlings differed remarkably from the development of embryos of Serbian spruce. In the control, somatic embryos of Norway spruce had much longer hypocotyls than radicles (Fig. 4). The embryos dried at relative humidity of $97 \%$, produced slightly shorter hypocotyls and much longer radicles, compared with the control (Fig. 4), which indicates a more synchronized development of both plant organs.

The highest average radicle length $(6.86 \mathrm{~mm})$ was obtained for embryos dried at the high relative humidity for 
Table 3 Germination capacity and conversion rate of somatic embryos of selected lines of Norway spruce (Picea abies) and Serbian spruce (P. omorika) after drying at specified relative humidity levels

\begin{tabular}{clccll}
\hline Species & $\begin{array}{l}\text { Relative humidity during } \\
\text { drying }\end{array}$ & $\begin{array}{l}\text { Drying } \\
\text { period } \\
\text { (weeks) }\end{array}$ & $\begin{array}{l}\text { No. of } \\
\text { embryos }\end{array}$ & $\begin{array}{l}\text { Germination } \\
(\%)\end{array}$ & $\begin{array}{l}\text { Conversion } \\
(\%)\end{array}$ \\
\hline $\begin{array}{r}\text { Norway } \\
\text { spruce }\end{array}$ & Control (no drying) & 0 & 258 & $99.31 \pm 0.70$ & $2.21 \pm 1.24$ \\
& $97 \%$ & 2 & 47 & 100.00 & $45.26 \pm 7.39$ \\
& $79 \%$ & 3 & 55 & 100.00 & $42.27 \pm 2.96$ \\
& & 2 & 59 & $4.76 \pm 4.76$ & 0.00 \\
Serbian & Control (no drying) & 3 & 61 & 0.00 & 0.00 \\
spruce & $97 \%$ & 2 & 415 & $92.55 \pm 2.07$ & $3.41 \pm 1.78$ \\
& & 3 & 54 & $92.06 \pm 7.94$ & $4.76 \pm 4.76$ \\
& $79 \%$ & 2 & 57 & 100.00 & $3.27 \pm 1.65$ \\
& & 3 & 56 & $0.26 \pm 9.26$ & 0.00 \\
& & & & 0.00 & 0.00
\end{tabular}

Mean \pm standard error

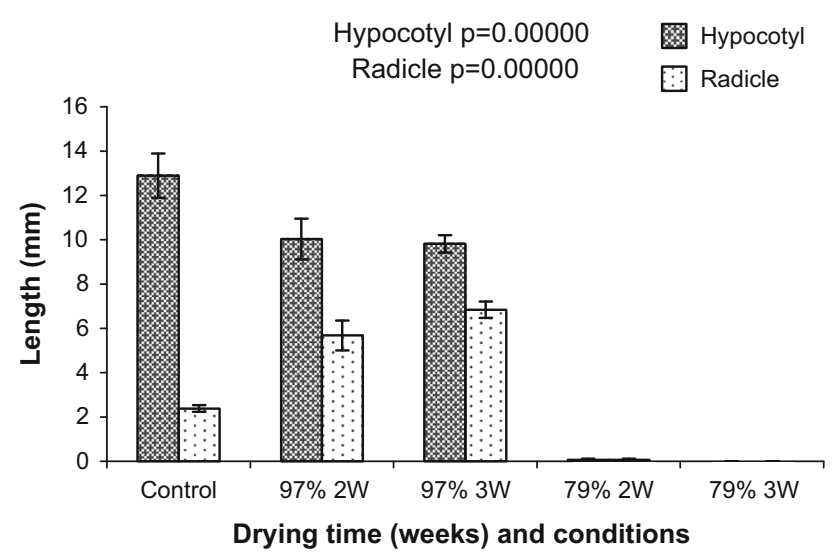

Fig. 4 Effect of partial drying or desiccation at specified relative humidity levels for 2 and 3 weeks $(W)$ on hypocotyl and radicle length in germinating somatic embryos of Norway spruce (Picea abies). Mean \pm standard error

3 weeks (Fig. 4). This result is 3 -fold higher than in the control $(2.38 \mathrm{~mm})$.

Partial drying of Norway spruce somatic embryos at high relative humidity led to an over 20 -fold increase in the rate of conversion of embryos into seedlings (to about $45 \%$ ), as compared with the control (Table 3). Somatic seedlings of Norway spruce obtained in this way exhibited organized development, manifested by a well-developed radicle, with the first root hairs (Fig. 6) and needles surrounding the apical bud (Fig. 7).

In contrast, the control somatic embryos of Serbian spruce were characterized by a more synchronized development, where the hypocotyl and radicle length did not differ as much as in Norway spruce embryos (Figs. 4, 5). After drying of embryos at high relative humidity (97\%), synchronization of radicle and hypocotyl growth was lower, due to a more intensive growth of the radicle (almost twice as long) and a similar increase in hypocotyl

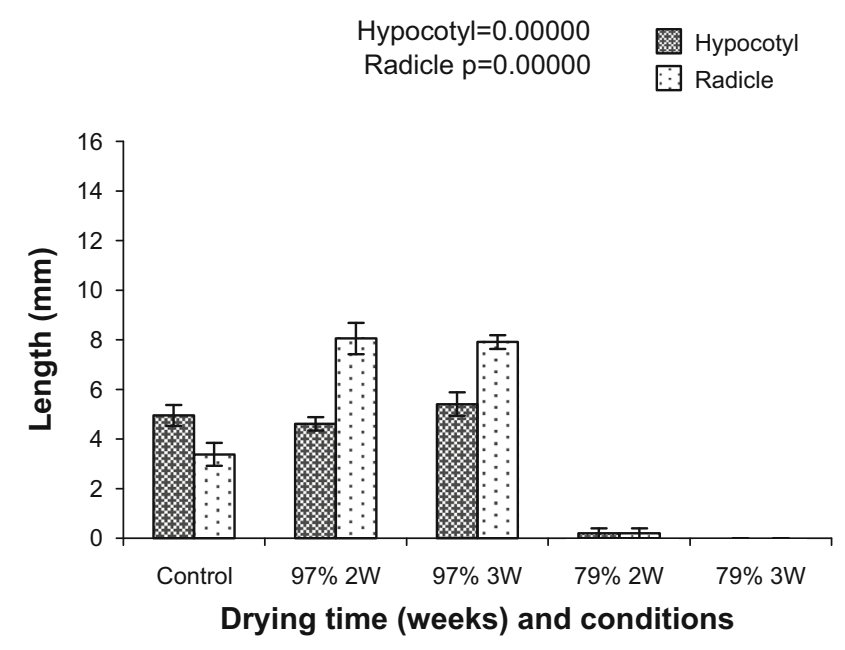

Fig. 5 Effect of partial drying or desiccation at specified relative humidity levels for 2 and 3 weeks $(W)$ on hypocotyl and radicle length in germinating somatic embryos of Serbian spruce (Picea omorika). Mean \pm standard error

length, compared with the control (Fig. 5). Therefore, in this species, conversion of embryos into somatic seedlings (Table 3) was hampered by a $26 \%$ water loss (Table 2 ).

\section{Discussion}

We used two media for germination of somatic embryos of Norway and Serbian spruce (ME or BM-5). More than $90 \%$ of somatic embryos were able to germinate on both media. The BM-5 medium proved to be more effective in terms of synchronization of hypocotyl and radicle growth (especially in Serbian spruce). However, the embryos cultured on this medium often showed abnormal growth (swollen hypocotyl, poorly developed cotyledons). Therefore, the BM-5 medium proved to be useless for 


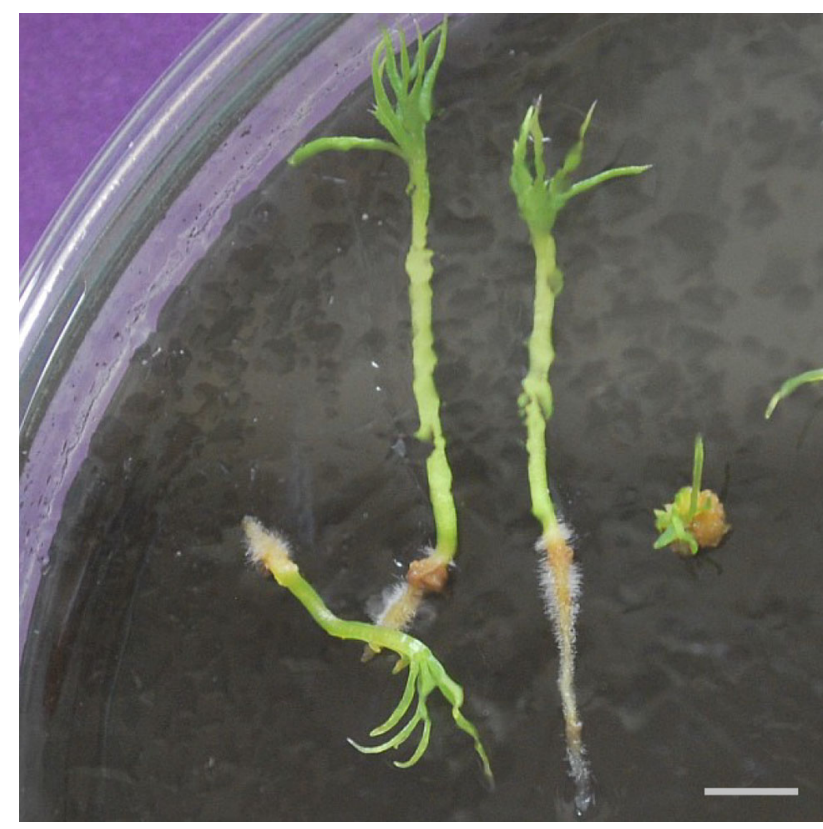

Fig. 6 Seedlings of Norway spruce (Picea abies) with well-developed root hairs, after germination on ME medium of somatic embryos that had been partially dried at $97 \%$ relative humidity. Bar $5 \mathrm{~mm}$

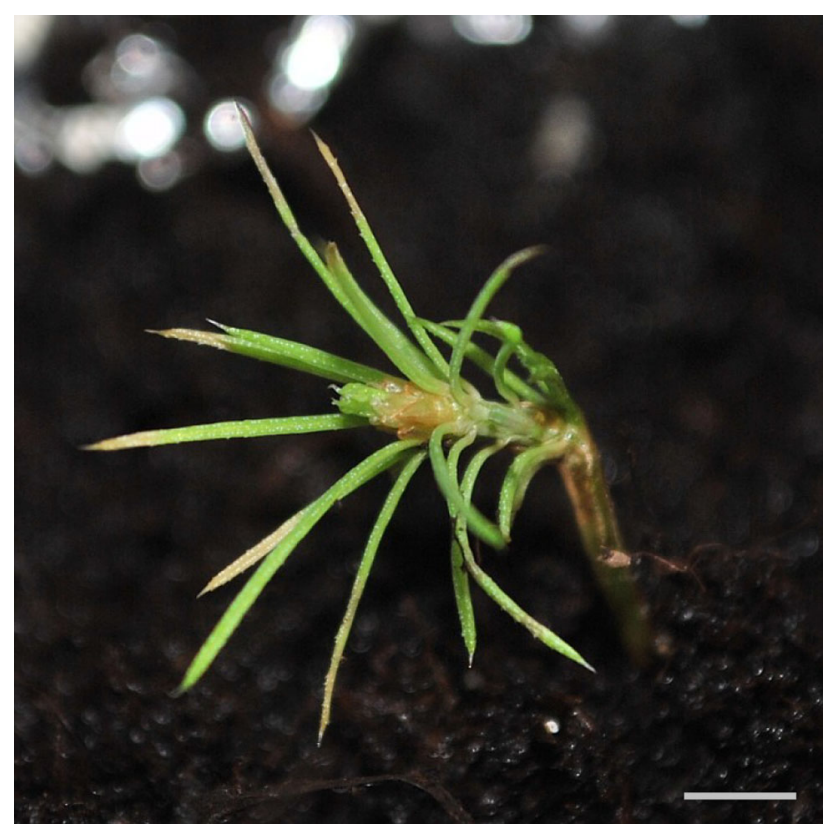

Fig. 7 Typical somatic seedling of Norway spruce (Picea abies), with first needles visible around the apical bud, obtained after partial drying of embryos at $97 \%$ relative humidity. Bar $10 \mathrm{~mm}$

germination of both spruce species. Somatic embryos incubated on the ME medium were characterized by normal morphology of the radicle and hypocotyl. However, the growth intensity of hypocotyl and radicle differed significantly. Slow synchronization of hypocotyls and radicle growth of seedlings of both spruce species have been already observed in our previous study during incubation of somatic embryos on the ME medium (HazubskaPrzybył and Bojarczuk 2008). For comparison, Bercetche (1989) successfully applied the ME medium for germination of Norway spruce somatic embryos. The author reported that about $40 \%$ of the embryos produced the first needles after 2 weeks of incubation on this medium. In our previous experiments, the formation of the first needles took place after at least 4 weeks of incubation of the somatic embryos on ME medium (unpublished data).

In our study, the majority of somatic embryos produced very short radicles $(2-3 \mathrm{~mm})$ regardless of the type of medium used. Consequently, the conversion rate was very low (2\% for Norway spruce and $3 \%$ for Serbian spruce), which prevented obtaining high-quality somatic seedlings of both species. In earlier studies, the conversion rate of somatic embryos of Norway spruce into seedlings was 5-35 \% (von Arnold and Hakman 1988; Becwar 1993; Hay and Charest 1999). For other coniferous species, the conversion capacity varied widely: 7-92\% in Larix $\times$ leptoeuropea (Lelu et al. 1995); $49 \%$ in Pinus caribaea (David et al. 1995) and 80-92\% in Picea glauca (Attree et al. 1994).

To improve the quality of seedlings of both spruce species, we subjected somatic embryos to relative humidity of 79 or $97 \%$ and then incubated them on the ME germination medium. Partial drying of somatic embryos at the higher relative humidity contributed to a significant improvement of embryonic radicle growth in both species (Figs. 4, 5). Consequently, an improvement of the conversion rate of somatic embryos of Norway spruce in the seedlings from 2 to $45 \%$ (Table 3 ) was noticed. In the case of somatic embryos of Serbian spruce, the conversion rate did not change, in spite of the applied treatment. This was manifested by the unequal and poor growth of hypocotyls (less than $10 \mathrm{~mm}$ ), which was unaffected by partial drying at relative humidity of $97 \%$ (Fig. 5).

Many studies have shown a positive effect of drying/ desiccation of mature somatic embryos of conifers on germination and conversion (Roberts et al. 1990; Hogberg et al. 2001; Pond et al. 2002; Szczygieł et al. 2007; Maruyama and Hosoi 2012). Roberts with co-workers (1990) were able to increase the germination efficiency of somatic embryos of interior spruce (a mixture of Picea glauca and $P$. engelmannii from the interior of British Columbia) to $90 \%$ following treatment at humidities greater than $95 \%$. Szczygieł and colleagues (2007) improved the germination capacity of somatic embryos of Norway spruce by partial drying at relative humidity of 95-97\%. After 4 weeks of treatment, over $80 \%$ of embryos were capable of germination. In the case of silver fir somatic embryos, the high capacity for germination (69-79\%) was obtained after 3 weeks of drying (Szczygieł et al. 2007). Recently, 
Maruyama and Hosoi (2012) improved germination and conversion rate of somatic embryos of the three Japanese pine species (Pinus thunberghii, $P$. densiflora, and $P$. armandii var. amamiana) using the slow drying of embryos at high relative humidity (98\%). Germination capacity and conversion rate increased from 19 to $81 \%$, and from 15 to $77 \%$, respectively, compared with the undried control.

A few reports indicate no effect or a negative effect of desiccation on germination and conversion of somatic embryos of conifers (Roberts et al. 1990; Attree et al. 1991; Bomal and Tremblay 1999). Desiccation of somatic embryos of white spruce at relative humidity of $81 \%$ did not contribute to improvement of germination and subsequent development into plantlets (Attree et al. 1991). This procedure proved to be ineffective also in the case of somatic embryos of black spruce (Picea mariana Bomal and Tremblay 1999). Undried somatic embryos germinated and converted into plantlets at rates similar to embryos desiccated at relative humidity of $79 \%$ or more. Desiccation treatment at relative humidity of $81 \%$ proved to be lethal to somatic embryos of interior spruce (Roberts et al. 1990). This last result is similar to our results, because desiccation of somatic embryos of both spruce species at relative humidity of $79 \%$ for 2 and 3 weeks proved to be negative or lethal for most of them.

To induce normal germination of the embryo of dry spruce seeds, a $61 \%$ decrease in moisture content is required. In the case of somatic embryos, which are sensitive to severe water loss, a much lower decrease of moisture content is enough (about $5 \%$ ) to achieve proper germination (Roberts et al. 1990, 1991). Roberts et al. (1991), for example, improved germination and post-germinative growth and development of Picea sitchensis (sitka spruce) after reducing the moisture content by $15 \%$. Somatic embryos of different spruce species may respond in different ways to desiccation treatments. For example, for interior spruce, desiccation at relative humidity of $81 \%$ proved to be lethal (Roberts et al. 1990), while for black spruce, strong inhibition of root and hypocotyl growth were noticed only after desiccation at relative humidity of $63 \%$ (Bomal and Tremblay 1999). Similarly partial drying at relative humidity of $97 \%$ not always contributed to the improvement of germination and conversion rates of somatic embryos of spruces (Bomal and Tremblay 1999).

In our study, only partial drying contributed to improvement of germination rate in both spruce species. We obtained also better conversion of Norway spruce somatic embryos after this treatment. Desiccation at relative humidity of $79 \%$ proved to be ineffective for improving the quality of somatic seedlings, because of excessive water loss (more than $60 \%$ ). Poor growth of somatic embryos of Serbian spruce hypocotyls after partial drying at relative humidity of $97 \%$ results in our opinion from the quality and genotype of the embryos taken for drying. Bomal and Tremblay (1999) showed that during desiccation of somatic embryos of black spruce under different relative humidities $(97,88,79$ and $63 \%$ ), hypocotyl elongation was always inhibited, but this did not affect plantlet conversion. We observed the same phenomenon in Norway spruce somatic embryos (Fig. 4). The length of hypocotyls of Serbian spruce somatic embryos after partial drying at relative humidity of $97 \%$ was similar to the hypocotyl length of control embryos whereas there were significant differences in the length of radicles of germinating embryos relative to the control (Fig. 5). Thus the effect of partial drying on hypocotyls of Serbian spruce growth was low. Nutritional, physical, and chemical conditions used in the earlier stages of the development of somatic embryos may affect their quality and, consequently, their subsequent ability to grow in somatic seedlings (Bozhkov and von Arnold 1998; Hay and Charest 1999; Hogberg et al. 2001). For example, application of the higher concentration of sucrose $(6 \%)$ during maturation of black spruce somatic embryos resulted in the induction of high germination and plantlet development (Bomal and Tremblay 1999). Somatic embryos of Serbian spruce matured in the presence of $3.4 \%$ of sucrose and thus the osmotic potential of the medium was not enough to provide a natural draught stress during embryogenesis, which could improve the germination and conversion into plantlets. However, in our previous work we observed that somatic embryos of some lines of Serbian spruce matured in the medium supplemented with this concentration of sucrose were capable of high conversion (60-100\%) without the drying phase (Szczygieł et al. 2007). Thus, we think that apart from the quality of somatic embryos of Serbian spruce after maturation, the influence of genotype of somatic embryos was also not without significance, although according to Park (2002) the genetic effects are the lowest in the whole somatic embryogenesis process at the germination stage.

Desiccation is a natural process that occurs in seeds in the final step of maturation (Angelovici et al. 2010). As a result of water loss the seeds prepare for quiescence and next for germination. In most species of conifers, partial drying or desiccation of somatic embryos is essential for the proper development of seedlings (Roberts et al. 1990; Find 1997; Bomal and Tremblay 1999). Drying/desiccation treatment causes changes in expression of genes involved in embryo maturation in favor of genes controlling germination (Kermode and Bewley 1985). During this treatment, multiple changes in transcriptional, post-transcriptional and metabolic processes are initiated (Angelovici et al. 2010). Dehydration initiates the desiccation tolerance program in the cells of the embryos, as evidenced by the increase in the concentration of non-reducing di- and 
oligosaccharides, compatible solutes and specific proteins (the late embryogenesis abundant proteins-LEAs and heat shock proteins-HSPs; Hoekstra et al. 2001).

In conclusion, we were able to improve the conversion rate and quality of Norway spruce somatic seedlings by partial drying, which confirms results of previous research on the effectiveness of this method. However, the results obtained for Serbian spruce were not satisfactory. This may have resulted from the genotype and condition of embryos collected for germination, which may require a special treatment at the maturation stage to improve their subsequent growth.

Author contribution statement (1) Project preparation: THP, (2) experiment design: THP, MW, AO, (3) experiment work: MW, AO, (4) data analysis: MW, THP, (5) manuscript draft: THP, MW, KB, (6) manuscript editing: THP, KB.

Acknowledgments This work was supported by the National Science Centre in Krakow, Poland (Narodowe Centrum Nauki, NCN, grant No. N N309 130837).

Open Access This article is distributed under the terms of the Creative Commons Attribution License which permits any use, distribution, and reproduction in any medium, provided the original author(s) and the source are credited.

\section{References}

Angelovici R, Galili G, Fernie AR, Fait A (2010) Seed desiccation: a bridge between maturation and germination. Trends Plant Sci 15(4):211-218

Attree SM, Moore D, Sawhney VK, Fowke LC (1991) Enhanced maturation and desiccation tolerance of white spruce (Picea glauca [Moench] Voss) somatic embryos: effect of a nonplasmolysing water stress and abscisic acid. Ann Bot 68:519-525

Attree SM, Pomeroy MK, Fowke LC (1994) Production of vigorous, desiccation tolerant white spruce (Picea glauca [Moench] Voss) synthetic seeds in bioreactor. Plant Cell Rep 13:601-606

Attree SM, Pomeroy MK, Fowke LC (1995) Development of white spruce (Picea glauca (Moench) Voss) somatic embryos during culture with abscisic acid and osmoticum and their tolerance to drying and frozen storage. J Exp Bot 46:433-439

Becwar MR (1993) Conifer somatic embryogenesis and clonal forestry. In: Ahuja MR, Libby WJ (eds) Clonal forestry I genetics and biotechnology. Springer, Berlin, pp 201-223

Bercetche J (1989) Optimisation des conditions d'obtention de plantules a partier de cals embryogenes chez Picea abies. Annal Afocel, pp 97-115

Bomal C, Tremblay FM (1999) Effect of desiccation to low moisture content on germination, synchronisation of root emergence, and plantlet regeneration of black spruce somatic embryos. Plant Cell Tiss Org Cult 56:193-200

Bozhkov PV, von Arnold S (1998) Polyethylene glycol promotes maturation but inhibits further development of Picea abies somatic embryos. Physiol Plant 104:211-224

David A, Laine E, David H (1995) Somatic embryogenesis in Pinus caribaea. In: Jain SM, Gupta PK, Newton RJ (eds) Somatic embryogenesis in woody plants. Kluwer Academic Publishers, Dordrecht, pp 145-182

Dronne S, Label P, Lelu MA (1997) Desiccation decreases abscisic acid content in hybrid larch (Larix $\times$ leptoeuropea) somatic embryos. Physiol Plant 99:433-438

Find JI (1997) Changes in endogenous ABA levels in developing somatic embryos of Norway spruce (Picea abies (L.) Karst.) in relation to maturation medium, dessication and germination. Plant Sci 128:75-83

Gupta PK, Holmstrom D (2005) Douglas-fir (Pseudotsuga menziesii). In: Jain SM, Gupta PK (eds) Protocol for somatic embryogenesis in woody plants. Springer, Dordrecht, pp 25-34

Hay EI, Charest PJ (1999) Somatic embryo germination and desiccation tolerance in conifers. In: Mohan JS, Gupta PK, Newton RJ (eds) Somatic embryogenesis in woody plants vol. 4. Kluwer Academic Publishers, Dordrecht, pp 61-69

Hazubska-Przybył T, Bojarczuk K (2008) Somatic embryogenesis of selected spruce species (Picea abies, P. omorika, P. pungens 'Glauca' and P. breweriana). Acta Soc Bot Pol 77(3):189-199

Hoekstra FA, Golovina EA, Buitink J (2001) Mechanism of plant desiccation tolerance. Trends Plant Sci 15(4):431-438

Hogberg KA, Bozhkov PV, Gronroos R, von Arnold S (2001) Critical factors affecting ex vitro performance of somatic embryo plants of Picea abies. Scand J For Res 16:295-304

Jones NB, Van Staden J (2001) Improved somatic embryo production from embryogenic tissue of Pinus patula. In Vitro Cell Dev Biol Plant 37:543-549

Kermode AR, Bewley JD (1985) The role of maturation drying in the transition from seed development to germination. J Exp Bot 36(173):1906-1915

Lazzeri PA, Hildebrand DF, Collins G (1987) Soybean somatic embryogenesis: effects of nutritional, physical and chemical factors. Plant Cell Tiss Org Cult 10:209-220

Lelu MA, Klimaszewska K, Pflaum G, Bastien C (1995) Effect of maturation duration on desiccation tolerance in hybrid larch (Larix $\times$ leptoeuropaea Dengler). In Vitro Cell Dev Biol Plant $31: 15-20$

Litvay JD, Verma DC, Johson MA (1985) Influence of loblolly pine (Pinus taeda L.) culture medium and its components on growth and somatic embryogenesis of wild carrot (Daucus carota L.). Plant Cell Rep 4:325-328

Margara J (1977) La multiplication vegetative de la betterave (Beta vulgaris L.) en culture in vitro. CR Acad Sci 285:1041-1044

Maruyama TE, Hosoi Y (2012) Post-maturation treatment improves and synchronizes somatic embryo germination of three species of Japanese pines. Plant Cell Tiss Org Cult 110:45-52

Park YS (2002) Implementation of somatic embryogenesis in clonal forestry: technical requirements and deployment considerations. Ann For Sci 59:651-656

Park YS, Barret JD, Bonga M (1998) Application of somatic embryogenesis in high-value clonal forestry: deployment, genetic control and stability of cryopreserved clones. In Vitro Cell Dev Biol Plant 34:231-239

Pond SE, von Aderkas P, Bonga JM (2002) Improving tolerance of somatic embryo of Picea glauca to flash desiccation with a cold treatment (desiccation after cold acclimation). In Vitro Cell Dev Biol Plant 38:334-341

Roberts DR, Sutton BCS, Flinn BS (1990) Synchronous and high frequency germination of interior spruce somatic embryos following partial drying at high relative humidity. Can J Bot 68:1086-1090

Roberts DR, Lazarof WR, Webster FB (1991) Interaction between maturation and high relative treatments and their effects on germination of sitka spruce somatic embryos. J Plant Physiol 138:1-6 
Rockland LB (1960) Saturated salt solutions for static control of relative humidity between 5 and $40{ }^{\circ} \mathrm{C}$. Anal Chem 32(10): 1375-1376

Stasolla C, Yeung EC (2003) Recent advances in conifer somatic embryogenesis: improving somatic embryo quality. Plant Cell Tiss Org Cult 74:15-35

Szczygieł K, Hazubska-Przybył T, Bojarczuk K (2007) Somatic embryogenesis of selected coniferous tree species of the genera Picea, Abies and Larix. Acta Soc Bot Pol 7(1):7-15
Uddin MR, Keinonen-Mettala K, Dinus RJ (1989) Enhanced germination of Norway spruce somatic embryos. IPC Tech Pap Ser 343:1-11

von Arnold S, Hakman I (1988) Regulation of somatic embryo development in Picea abies by abscisic acid (ABA). J Plant Physiol 132:164-169

Webster FB, Roberts DR, McInnis SM, Sutton SC (1990) Propagation of interior spruce by somatic embryogenesis. Can J For Res 20:1759-1765 